\title{
Are martial arts and combat sports a school for life? Relationships between sport attitudes and quality of life (intermediate results)
}

\author{
Bruno AVELAR-ROSA ${ }^{* 1,2,3}$, António M. M. QUARESMA ${ }^{4}$, \& Jorge AREDE3,5 \\ ${ }^{1}$ Luso-Ilyrian Institute for Human Development (iLIDH) (Portugal) \\ ${ }^{2}$ Universidade Europeia (Portugal) \\ ${ }^{3}$ Universitat de Girona (Spain) \\ ${ }^{4}$ Independent researcher (Portugal) \\ ${ }^{5}$ Universidade de Trás-os-Montes e Alto Douro (Portugal)
}

\section{5th IMACSSS World Scientific Congress Abstracts, Rio Maior (Portugal), October 6-8 Section: Historical, sociological and philosophical issues of MA\&CS Type: Oral communication}

\section{Introduction}

Quality of Life (QoL) is an indicator of health status and represents a multidimensional psychological construct describing multidimensional wellbeing (Erhart, et al., 2009). There are evidences that sport and physical activity promote QoL (WHO, 2013) and that enables the development of values in young people (Whitehead, Telfer, \& Lambert, 2013). Complementarily, martial arts and combat sports (MA\&CS) are well known as practices with potential to develop personal and social values in its practitioners (Yonezawa, 2010; Cynarski, 2012, 2014), with psychological (Vertonghen \& Theeboom, 2010) and health benefits (Woodward, 2009). The purposes of this study are: (1) explore the associations between Sport Attitudes (SA) and QoL of adolescent's athletes; (2) account the differences between gender and age; and, (3) compare the differences of SA and QoL between sample groups.

\section{Methodology}

Web-based Portuguese validated questionnaires were used to assess SA (SAQ - Sport Attitudes Questionnaire; Gonçalves, Silva, Chatzisarantis, Lee, \& Cruz, 2006) and QoL (Kidscreen-27; Gaspar \& Matos, 2008). SAQ is divided in four dimensions: pro-social - commitment and convention; and, anti-social - cheating and gamesmanship. Kidscreen-27 is composed by five dimensions: physical wellbeing (PHW); psychological wellbeing (PSW); parent relations and autonomy; social support and peers (SSP); and, school (SCH). Athletes answered after notification by their coaches and investigation group request. Sample comprised 334 athletes (167 boys) of all the respondents ( $M=14,72 \pm 1,20$; range: 12-17 years).Three different groups were defined: MA\&CS - 68 (42 boys); Team Sports (TS) - 188 (87 boys); and, Individual Sports (IS) - 71 (36 boys). Most of MA\&CS group was composed essentially with karate $(72 \%)$ and judo (15\%) athletes. The majority of TS group was composed with basketball (30\%), football (29\%), volleyball $(28 \%)$ and water polo (8\%) athletes. The IS group was composed with canoeing (31\%), kayak $(16 \%)$, athletics $(10 \%)$ and swimming (9\%) athletes. All statistical analyses were performed using IBM SPSS Statistics version 21. Pearson correlations, independent-sample t-test and, analyses of variance (ANOVA) were conducted and post hoc multiple comparisons (LSD and Dunnet C) were applied to compare all groups of participants with each other.

\section{Results}

The MA\&CS group presented only negative correlations between cheating $(r=-.301, n=68, p=.013)$, gamesmanship ( $\mathrm{r}=-.285, \mathrm{n}=68, \mathrm{p}=.019$ ) and QoL SSP. Furthermore, commitment showed positive 
correlations between QoL PHW, SSP and, SCH ( $\mathrm{p}=.020$ to $\mathrm{p}=.011)$. Age showed no significant associations, and there were no gender differences in any dimension of QoL or SA. Considering TS and IS group together there were: no significant associations between negative dimensions of SA and QoL; positive associations between all positive dimensions of SA and QoL ( $\mathrm{p}=.009$ to $\mathrm{p}<.001)$; negative correlations with age and all dimensions of QoL, except for PHW ( $\mathrm{p}=.049$ to $\mathrm{p}<.001$ ); and no correlations with age and SA. Boys report more PHW ( $\mathrm{t}=4.194, \mathrm{df}=257, \mathrm{p}<.001)$ and PSW $(\mathrm{t}=2.656, \mathrm{df}=257, \mathrm{p}=.008)$, but report also more cheating $(\mathrm{t}=2.108, \mathrm{df}=216.323, \mathrm{p}=.036)$ and gamesmanship ( $\mathrm{t}=2.141, \mathrm{df}=235.988, \mathrm{p}=.033)$. Comparing the three sample groups we found that: MACS is lower in gamesmanship and convention than TS; MA\&CS is lower in QoL SSP than TS; and MA\&CS do not have significant differences with IS on SA and QoL.

\section{Discussion and conclusion}

MA\&CS athletes' data suggests that the negative correlations between negative SA and social support and peer QoL reflects the true nature of MA\&CS training - "train with, not against". On the other hand, the non MA\&CS group results on the relation of QoL and positive/negative attitude, suggests the idea that sports could be a school of life. Furthermore, MA\&CS group progression with age and the differences by gender are quite different from the non MA\&CS group, which follows the world trend (Erhart, et al., 2009), and that leads us to propose that MA\&CS can help to curb this trend.

\section{References}

Cynarski, W. (2012). Values of Martial Arts in the light of the anthropology of Martial Arts. Journal of Combat Sports and Martial Arts, 1(2), 1-4.

Cynarski, W. (2014). Moral values, and the people of the noble of Martial Arts. IDO Movement for Culture - Journal of Martial Arts Anthropology, 14(1), 1-10.

Erhart, M., Ottova, V., Gaspar, T., Jericek, H., Schnohr, C., Alikasifoglu, M., . . Ravens-Sieberer, U. (2009). Measuring mental health and well-being of school-children in 15 European countries using the KIDSCREEN-10 Index. International Journal of Public Health, 54(S2), 160-166.

Gaspar, T., \& Matos, M. (Eds). (2008). Versão Portuguesa dos instrumentos KIDSCREEN-52: Instrumentos de qualidade de vida para crianças e adolescentes (Portuguese version of KIDSCREEN-52: Instruments of quality of life in children and adolescents). Lisboa: FMH.

Gonçalves, C. E., Silva, M. J. C., Chatzisarantis, N., Lee, M. J., \& Cruz, J. (2006). Tradução e validação do SAQ (Sports Attitudes Questionnaire) para jovens praticantes desportivos portugueses com idades entre os 13 e os 16 anos. Revista Portuguesa de Ciências do Desporto, 6(1), 38-49.

Verthonghen, J., \& Theeboom, M. (2010). The Social-Psychological outcomes of Martial Arts practise among young: a review. Journal of Sports Science and Medicine, 9, 528-537.

Whitehead, J., Telfer, H., \& Lambert, J. (Eds.) (2013). Values in youth sport and physical education. London: Routledge.

Woodward, T. (2009). A review of the effects of martial arts practice on health. Wisconsin Medical Journal, 108(1), 40-43.

World Health Organization. (2013). Global action plan for the prevention and control of noncommunicable diseases 2013-2020. Retrieved from http://apps.who.int/iris/bitstream/10665/94384/1/9789241506236_eng.pdf?ua=1

Yonezawa, F. (2010). Algo se move: um elogio filosófico-ético à prática do combate como arte e educação. Motriz, 16(2), 348-358.

Key words: Martial arts; combat sports; ethics; values; youth development. 